\title{
“Double jeopardy": twin problems associated with an esophageal self-expanding metal stent
}

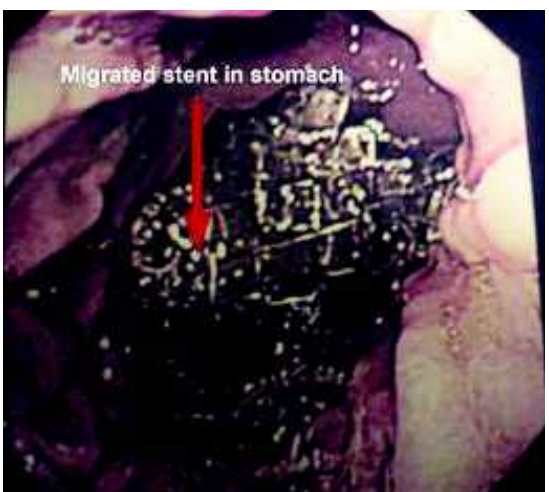

Fig. 1 Endoscopic image of the stent lying free in the stomach.

A 63-year-old man underwent placement of a self-expanding metal stent (SEMS) for palliation across a malignant esophageal stricture due to adenocarcinoma of the lower esophagus. He also underwent palliative chemotherapy with good radiological regression of the original tumor. He presented with dyspeptic symptoms 3 months after stent placement, and a gastroscopy revealed the stent to be lying free in the stomach ( $\bullet$ Fig. 1). An attempt was not made to retrieve the stent at the time. He presented again 2 weeks later with abdominal pain and vomiting. An abdominal radiograph revealed features of small-bowel obstruction with two fragments of the stent seen at different levels in the small bowel ( Fig. 2). A computed tomography scan of the abdomen confirmed this finding ( $\bullet$ Fig. 3). The distal fragment was identified to be lying in the distal ileum, with the proximal fragment in the distal jejunum/proximal ileum. Laparotomy revealed that the stent had indeed fractured into two fragments and that the distal end of the stent lay embedded in the ileal wall with a localized perforation ( $\odot$ Fig.4). A limited ileal resection and end-to-end anastomosis was performed. The patient had an uneventful recovery.

SEMS are prone to migration, and migration rates of $5 \%-32 \%$ have been reported,

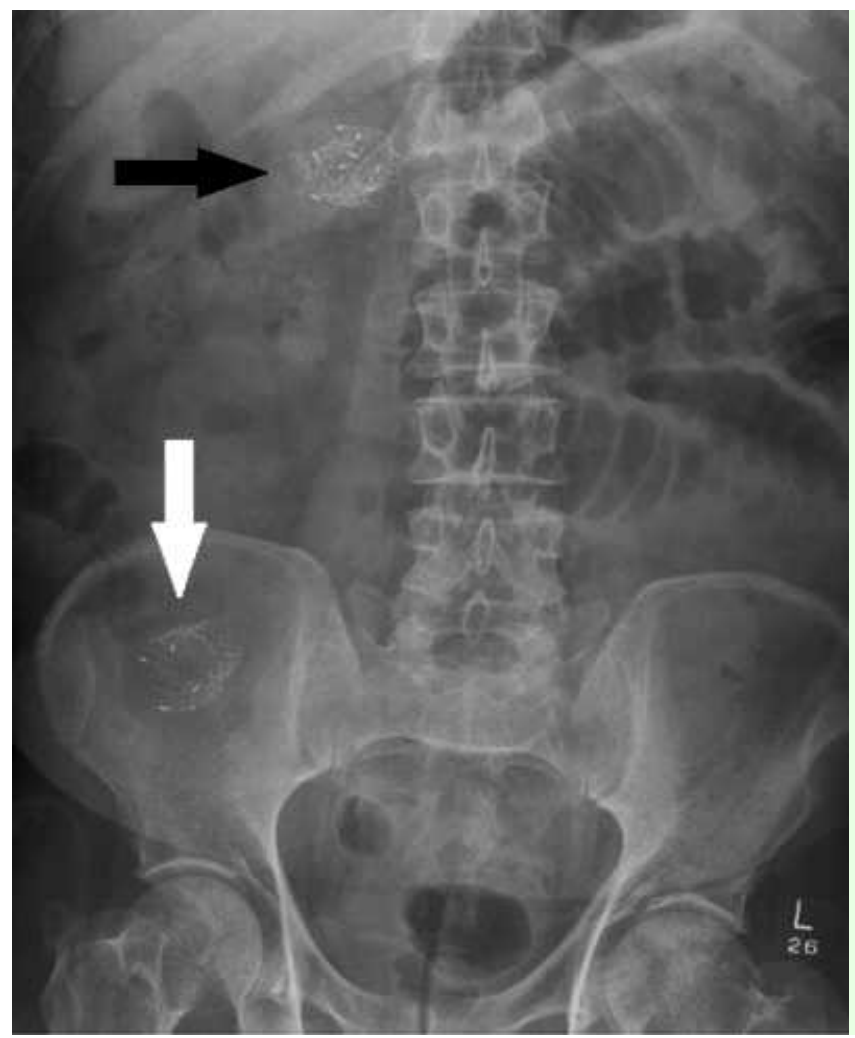

Fig. 2 Abdominal radiograph showing dilated loops of small bowel with the two fragments of the stent lying at different levels (black arrow: proximal end of the stent; white arrow: distal end).

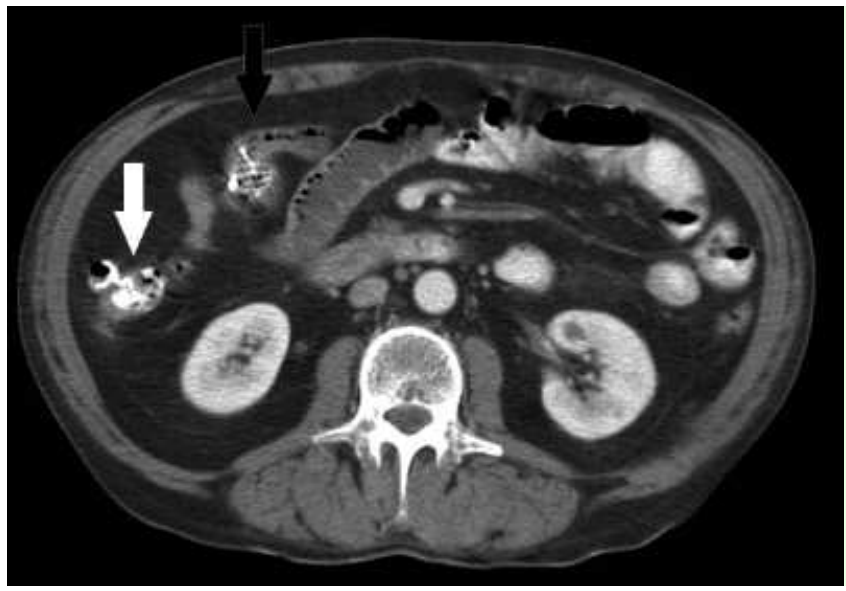

Fig. 3 Computed tomography scan of the abdomen revealing the two fragments of the stent (black arrow: proximal end of the stent; white arrow: distal end).

leading to intestinal obstruction in $4.3 \%$ of cases [1]. SEMS have also been known to fracture, and acid corrosion has been blamed for this complication [2,3]. Fractured stents are very likely to migrate and cause perforation and should there- fore be retrieved endoscopically, if possible, from the stomach.

Endoscopy_UCTN_Code_CPL_1AH_2AD 


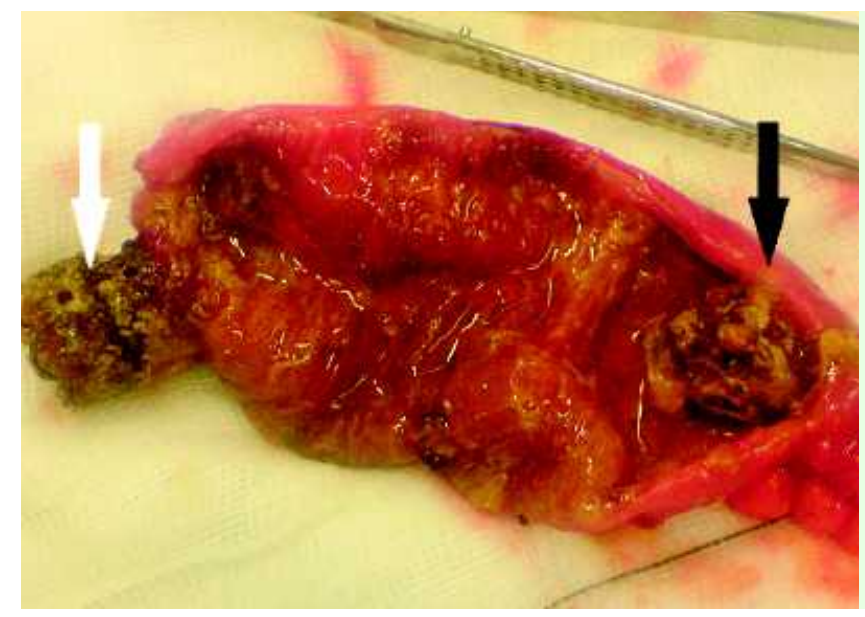

Fig. 4 Resected specimen of ileum with the distal end of the stent embedded in the ileal wall (site of the perforation, white arrow) and the proximal end of the stent lying free in the ileal lumen (black arrow).

S. Menon ${ }^{1}$, L. Mathew ${ }^{2}$, A. Munasinghe ${ }^{2}$, J. Butterworth ${ }^{1}$

1 Department of Gastroenterology, Princess Royal Hospital, Telford, UK

2 Department of Surgery, Princess Royal Hospital, Telford, UK
Bibliography

DOI 10.1055/s-2008-1077454

Endoscopy 2008; 40: E210-E211

(c) Georg Thieme Verlag KG Stuttgart · New York . ISSN 0013-726X

\section{Corresponding author}

\section{S. Menon, MRCP}

Department of Gastroenterology

Princess Royal Hospital

Telford TF6 1TF

UK

Fax: +44-1743-261066

s.menon@nhs.net 